\title{
Physical and chemical properties comparison of fungal and crustaceous chitosan
}

\author{
Wioletta Żukiewicz-Sobczak', Paweł Sobczak², Kazimierz Zawiślak², Jerzy Zagórski', \\ Paulina Wojtyła-Buciora ${ }^{3}$, Andrzej Wojtyła ${ }^{4}$ \\ 'Pope John Paul II State School of Higher Education in Biala Podlaska, Poland \\ 2Department of Food Engineering and Machines, University of Life Science, Lublin, Poland \\ ${ }^{3}$ Department of Physiology, University of Medical Sciences, Poznan, Poland \\ ${ }^{4}$ Higher Vocational State School in Kalisz, Poland
}

\begin{abstract}
In the paper we compared herein chemical properties of the fungal chitosan prepared according to the own method and the commonly used chitosan made from the crustaceous. The assessment included such parameters as: ash, fiber, fat, $\mathrm{Na}, \mathrm{K}, \mathrm{Ca}$ and $\mathrm{Mg}$ content. Inorganic phosphates, molecular weight and deacetylation degree were also determined. Based on these results a number of differences between substances was identified. The differences are related to varied structure that is due to different methods of two types of chitosan production. The difference in viscosity was the most pronounced parameter. It has been proved the viscosity of fungal chitosan was 5 times lower compared to crustaceous chitosan. The fungal chitosan was characterized with higher deacetylation degree (DD) than crustaceous chitosan. The deacetylation process has significant influence on the structure and chemical parameters of the chitosan. The chemical elements content was differentiation. Relatively low concentration of sodium was identified in the fungal chitosan. However, it contained high levels of nitrogen, fiber and fat when compared to the crustaceous chitosan.
\end{abstract}

KEY WORDS: fungal chitosan, crustaceous, viscosity.

ADDRESS FOR CORRESPONDENCE: Wioletta Żukiewicz-Sobczak, Department of Health, Pope John Paul II State

School of Higher Education in Biala Podlaska, 95/97 Sidorska St., 21-500 Biała Podlaska, Poland,

e-mail:wiola.zukiewiczsobczak@gmail.com

\section{INTRODUCTION}

There has been considerable interest in identifying and/or synthesizing new compounds that could be used in modern medicine. This is a great challenge for scientists, because the ideal compound should posses practically useful properties and meet all strict requirements. Such molecules, including therapeutic polysaccharides, should be characterized by low toxicity, degradability, low immune response. Certainly, it should be also cheap and easy to obtain or produce. Chitin and its derivative chitosan are naturally abundant and renewable polymers that combine some unique physical, chemical and biological features that are not found in other polymers.
These advantages include bioactivity, biodegradability, biocompatibility, some chelating and membrane- and fibre-forming properties. Such properties may explain different and wide practical application. Chitosan may serve as a controlling permeability and adhesiveness agent, a gluing paper, clearing, agglomering and chelating, antimicrobial, and chromatographic agent $[1,2]$. Chitosan may be also used for enzyme immobilization or to provide shield for enzyme inhibitors [1].

Chitin is frequently occurring natural polysaccharide produced by many living organisms. It is a component of the exoskeletons of crustaceans, mycelial/filamentous fungi and higher fungi $[3,4]$. 
Fungal chitin is produced in the process of biosynthesis in higher fungi. This product is renewable with respect to the continuity of cultivation Basidiomycetes in controlled conditions. It forms white, hard and poorly flexible structures. Chitin is hydrophobic and very weakly soluble in water and majority of common dilatants. Chitin is consider to be soluble in hexafluoroisopropanol, hexafluoroacetone or chloroalcohols [5].

Chitin, that is found in cellular walls of mycelial/ filamentous fungi and higher fungi, presents typical structure. This is a polymer of a simple chain constructed of $\beta$ - $(1,4)-\mathrm{N}$-acetylglucosamine, and classified as $\gamma$-chitin [6]. A number of fungi classes contain chitin, such as: Ascomycetes, Zygomycetes, Basidiomycetes, and Deuteromycetes [7]. In nature, $a$-chitin occurs more frequently and is found in the exoskeletons of crustaceans, such as crabs, shrimps and lobsters. The presence of non-parallel chain is characteristic for this type of chitin. Squids, however, poses $\beta$-chitin with parallel chain structure. Fungal chitin is a mixture of two types of chains occurring in $\alpha$ - and $\beta$-chitin [8].

In mass production chitosan from crustaceous shells is obtained during chemical deacetylation of chitin. Final product of this process is a polymer with a high level of deacetylation. Chitosans with better characteristics (higher deacetylation levels) are obtained as the result of an intensification of deacetylation conditions (temperature over $100^{\circ} \mathrm{C}$ and increased pressure), which

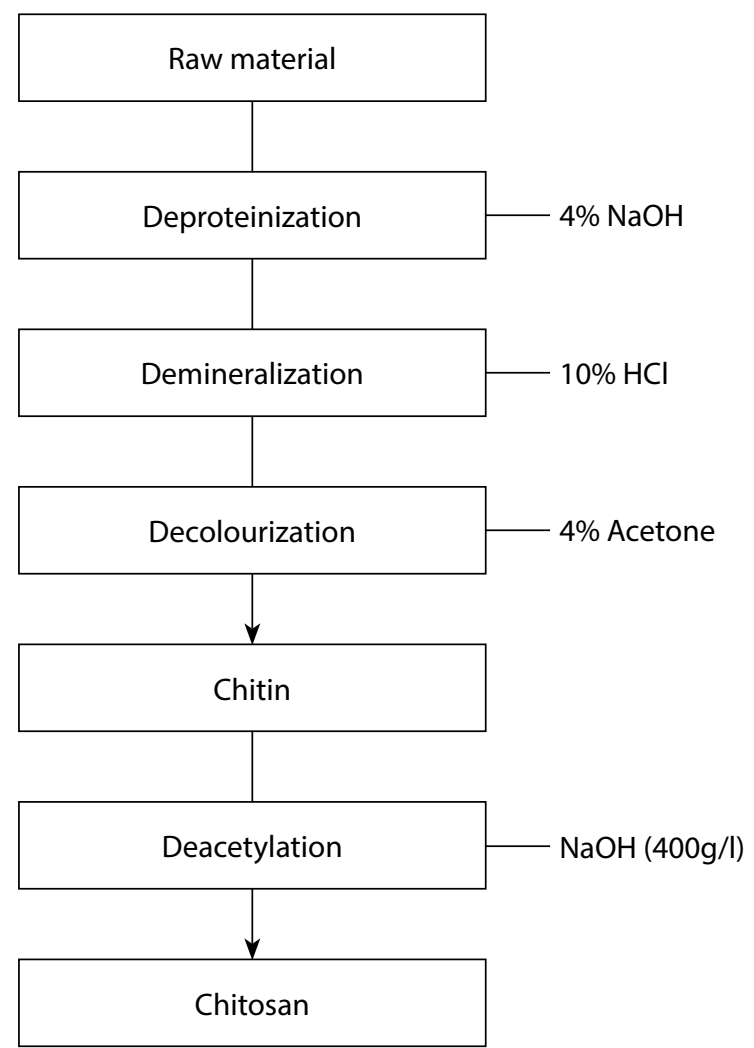

FIGURE 1. Scheme of obtaining fungal chitosan according to own method (patent reservation No. P-384836) leads to the simultaneous degradation of chitosan chain and considerably lower molecular weight $[3,5]$.

Chitosan is obtained from crustaceans and supplies of raw marine material are variable and have a seasonal character [8]. The laboratory process of chitosan production from crustaceans is very expensive. Another method used to obtain chitosan is the separation of chitin from cell walls of lower and higher fungi. The precise procedure of chitosan production from lower fungi has been known since 1979; however, this method has been not commonly applied due to the economic aspect and low efficiency. Chitosan is a natural component of the cell walls of filamentous fungi, such as Absidia, Mucor, Rhizopus, Gongronella [9], and of higher fungi belonging to Basidiomycetes. In the production of fungal chitosan, the aspect of a seasonal appearance does not occur [7]. The method of chitosan separation from filamentous fungi was developed by White, Farin and Fulton in 1979 [10].

Chitosan is a substance soluble in weak organic acids, and has a simple chain structure constructed of glucosamine and $\mathrm{N}$-acetyloglucosamine [11]. Unlike the majority of naturally occurring acidic or alkaline polysaccharides (dextran, cellulose or pectin), chitin and chitosan present strong alkaline reaction [5].

The most common type of chitosan available on the market is one derived from crustaceans. Identifying new sources of chitosan has been a challenge for many scientists [12]. For example, Draczynski obtained chitin from honey bee corpses [13]. The studies assessing the efficiency of obtaining chitosan from higher fungi included four species: Aspergillus niger, Rhizopus oryzae, Lentinus edodes, and Pleurotus sajo-caju. The effectiveness of chitosan production from the spawn biomass ranged from 10 to $140 \mathrm{mg} \times \mathrm{g}^{-1}$ (wet mass) [14].

Physical and chemical properties of chitosan are related to the process of $\mathrm{N}$-deacetylation. The longer time and the higher temperature of the process, the higher level of degradation of chitosan chain is observed. It could be monitored with the deacetylation degree (DD) and molecular weight of chitosan. The part of this process is depolymerization of chitosan chain, resulting in a lower molecular weight [12]. The process of $\mathrm{N}$-deacetylation positively affects chitosan solubility, that is useful property of this polysaccharide [15].

\section{MATERIAL AND METHODS \\ CHITOSAN}

Fungal chitosan used in the study was obtained according to previously described author's own method [16], presented in Figure 1. Chitosan from crustaceous shells was purchased by Sigma-Aldrich Inc., ST. Louis, Mo, USA. The spporocarp of Shi-take mushroom (Lentinus edodes) were reproduced according to the traditional method on a solid medium. Pure cultures of Lentinula edodes came from Laboratory for Pure Cultures of Higher Fungi at the Chair of Fruits, Vegetables and Fungi Technology (Lentinus edodes Le 323). 
Determination of dry mass content was performed using dryer method according to AACC, Method 44-15A. Measurement of raw ash content was done according to the standard AACC, Method 08-01. Fat content was determined by the extraction-weighting method (AACC, Method 20-26) [17]. Chitosan samples (3 g of weight) were subjected to extraction with hexane in Soxtec HT-6 system. Fiber content was assessed in the quantitative determination of the sample residue on suitably prepared filters. Mixtures of acetic nitric and trichloroacetic acids, together with the sample (brought to the boil), were subsequently filtered, then washed with hot distilled water. The filter was poured through with acetone, and subsequently placed in a dryer at $130^{\circ} \mathrm{C}$ for $1-2$ hours. Filters were weighed, and the results substituted to the formula:

$$
X=\frac{a \times 100 \%}{b}
$$

where: $b$ - mass of the sample, $a$ - mass of filter with the sample.

Results were presented as percentage.

Determination of $\mathrm{Na}, \mathrm{K}, \mathrm{Ca}, \mathrm{Mg}$ content was performed using atomic absorption spectrophotometry (acc. to AOAC-975.03). For determination of the elements by this method, Solaar 939, Pye Unicam atomic absorption spectrophotometer equipped with HCL lamps was used [18-20]. The samples were prepared by wet-mineratization.

Inorganic phosphates were determined_by the FiskeSubbarow method in 1925 [21].

In an acidic environment orthophosphate together with ammonium molybdate form ammonium phosphomolybdate. Due to the effect of reducing agents, phosphomolybdate acid is reduced to mixed molybdate oxides, so-called molybdate blue $\left(\mathrm{Mo}_{2} \mathrm{O}_{5} \times \mathrm{MoO}_{3}\right)$. Many colorimetric methods used to determine orthophosphates are based on this principle. Assessments of the proper surface, mesospores volume and mean mesospores diameter were performed using ASAP 2405 (Micromeritics Inc., USA). The measurements covered the plotting of nitrogen adsorption isotherm of high purity at the temperature of liquid nitrogen BET [22]. The equation of BET polymolecular adsorption isotherm is as follow:

$$
\frac{p}{V\left(p_{0}-p\right)}=\frac{1}{V_{m} \times c}+\frac{c-1}{V_{m} \times c} \times \frac{p}{p_{0}}
$$

where: $V$ - total volume of adsorbant adsorbed under the pressure $\mathrm{p}\left(\mathrm{cm}^{3}\right), V_{m}$ - adsorbat volume with the total coating of the adsorbent with monomolecular layer $\left(\mathrm{cm}^{3}\right), p$ - equilibrium pressure equivalent to the volume of the adsorbent adsorbed $\mathrm{V}$ in condition $\mathrm{p}$ [measurement $(\mathrm{mmHg})], p_{0}$ - pressure of saturated adsorbent vapor $(\mathrm{mmHg}), c$ - adsorption equilibrium constant associated with the difference between the adsorption warmth of the first layer and condensation warmth.

The proper surface $\mathrm{S}_{\mathrm{BET}}$ is calculated according to the formula [23]:

$$
S_{B E T}=\frac{V_{m} \times N_{A} \times a_{m}}{M \times V_{L}}\left[\mathrm{~m}^{2} / g\right]
$$

where: $N_{A}$ - Avogadro's number $\left(6,022 \times 10^{23} \mathrm{~mol}^{-1}\right)$, $a_{m}$ - surface of nitrogen molecule settling $\left(16,2 \times 10^{-20} \mathrm{~m}^{2}\right)$, $M$ - adsorbat molecular weight $(\mathrm{g} / \mathrm{mol}), V_{L}$ - nitrogen molecular volume $\left(22414 \mathrm{~cm}^{3}\right)$.

The volume, surface and mean mesospores diameters were determined using BJH method [24], in which calculations are based on Kelvin's equation (assuming cylinder-shaped pores):

$$
\ln \frac{p_{0}}{p}=-\frac{2 \gamma V_{L}}{r R T} \cos \theta
$$

where: $p_{0}$ - non-saturated vapor pressure over the flat liquid surface $(\mathrm{mmHg}), p$ - saturated vapor pressure over the meniscus of the radius of curvature $\mathrm{r}(\mathrm{mmHg})$, $\gamma$ - surface tension of liquid adsorbent, $V_{L}$ - molar volume of liquid adsorbent, $R=0.008314510 \mathrm{~kJ} /(\mathrm{mol} \times \mathrm{K})$ $=8.31434 \mathrm{Nm} /(\mathrm{mol} \times \mathrm{K})$ gas constant, $T-$ absolute temperature $(\mathrm{K}), \theta$ - angle of wetting pores walls with liquid adsorbent (for nitrogen $\theta=0$ ).

Chitosan molecular weight was determine using the viscosity method Mv. Chitosan samples were dissolved in a diluents system, consisting of acid (0.1 M) and sodium chloride $(0.2 \mathrm{M})$. The Brookfield digital viscometer (Model DV-II+, Stoughton, USA) reading was substituted to the formula according to the Marck-Houwink-Sakurada empirical equation method $[5,25]$.

$$
[\eta]=\mathrm{Km}(\mathrm{Mv})^{\alpha}
$$

where: $[\eta]$ - actual viscosity, $K m-1.81 \times 10^{-3}, \alpha-0.93$.

Deacetylation degree (DD) was calculated according to the method by $\mathrm{Xu}, \mathrm{McC}$ arthy and Gross [26]. C and $\mathrm{N}$ results from $\mathrm{CHN}$-os analysis were substituted to the formula:

$$
D D=\left[1-\frac{\mathrm{C} / \mathrm{N}-5.14}{1.72}\right] \times x 100
$$

where: $D D$ - deacetylation degree, $C / N$ - carbon to nitrogen ratio, 5.14 - constant, 1.72 - constant.

\section{STATISTICAL METHODS}

The results obtained at particular stages of our experiment were subject to statistical analysis. General statistical procedures associated with the evaluation of mean values, errors, and standard deviations, as well as $95 \%$ confidence intervals were performed. Selected 
plots present results of difference significance analysis (Tukey's test) between mean values of tested indicator. All statistical computations were made by applying standard procedures using Statistica software package, with the significance level of $\alpha=0.05$. The number of replicates was 3 for each analysis.

\section{RESULTS AND DISCUSSION}

Results of dry mass, humidity and raw ash measurements are shown at Figure 2. Chitosan obtained from crustaceous shells, of an average molecular weight $(91.80 \%)$, was characterized by the highest content of dry mass, whereas that of the high molecular weight $(86.77 \%)$ - with the lowest content. Dry mass of fungal chitosan was $89.42 \%$.

Chitosan with higher molecular weight was characterized by the highest humidity (13.23\%), while fungal chitosan by the lowest one (10.58\%). The humidity of examined chitosans ranged from $8.20 \%$ to $13.23 \%$.

In all samples trace amounts of raw ash were found (0.002-0.005\% d.m.).
The comparison of chemical parameters of different chitosan samples and of fungal chitin are presented in Table 1.

Fungal chitosan was characterized by the highest amount of fat $(0.38 \%)$, while chitosan derived from crustaceous shells of low molecular weight - by the lowest one $(0.10 \%)$. Chitosan from crustaceans of an average molecular weight and high molecular weight contained $0.21 \%$ and $0.29 \%$ of raw fat respectively. Fungal chitin contained $1.04 \%$ of raw fat.

The highest content of fiber was noted in fungal chitosan (4.60\%), while the lowest one was observed in crustaceous chitosan of an average (1.46\%) and low molecular weight (1.45\%). Fiber content was 3.90\% in chitosan obtained from crustaceous shells, whereas in fungal chitin $77.91 \%$.

The results of selected biochemical parameters of fungal and crustaceous chitosans are shown in Table 2. The highest content of sodium was observed in crustaceous chitosan of an average molecular weight $(8.60 \mathrm{mg} / \mathrm{kg})$. Sodium content in fungal chitosan was $1.93 \mathrm{mg} / \mathrm{kg}$, while in crustaceous chitosan of high molecular weight, twice as much $-3.50 \mathrm{mg} / \mathrm{kg}$.

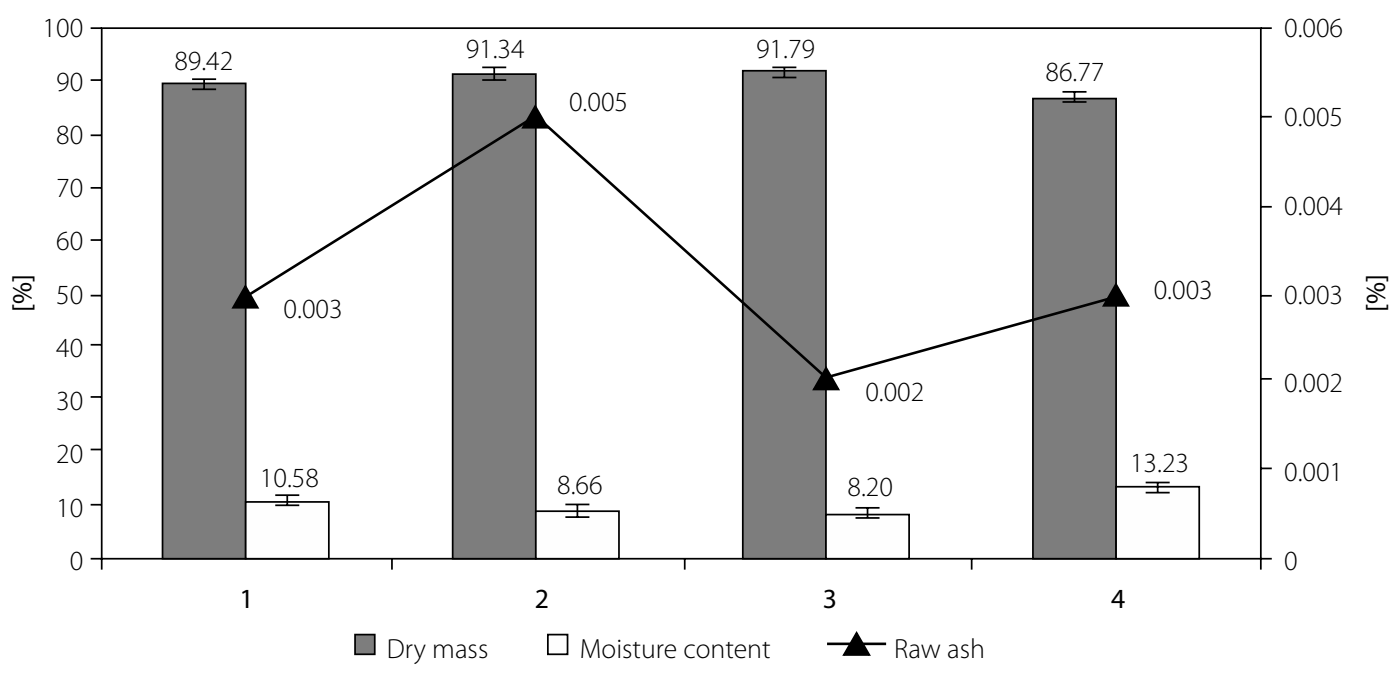

1. Fungal chitosan

2. Chitosan from crustaceous shells of low molecular weight

3. Chitosan from crustanceous shells of an average molecular weight

4. Chitosan from crustanceous shells of high molecular weight

FIGURE 2. Percentage content of dry mass, moisture content and raw ash in fungal and crustaceous chitosan

TABLE 1. Results of analysis of chemical composition of fungal and crustaceous chitosans

\begin{tabular}{|l|c|c|}
\hline Sample & Fat [\%] & Fibre [\%] \\
\hline Fungal chitosan & 0.38 & 4.60 \\
\hline Crustaceous chitosan of low molecular weight & 0.10 & 1.45 \\
\hline Crustaceous chitosan of average molecular weight & 0.21 & 1.46 \\
\hline Crustaceous chitosan of high molecular weight & 0.29 & 3.90 \\
\hline Fungal chitin & 1.04 & 77.91 \\
\hline
\end{tabular}


TABLE 2. Content of selected elements in fungal chitosan and chitosan obtained from crustaceous shells

\begin{tabular}{|l|c|c|c|c|c|}
\hline Sample & $\begin{array}{c}\mathrm{Na} \\
{[\mathrm{mg} / \mathrm{kg}]}\end{array}$ & $\begin{array}{c}\mathrm{K} \\
{[\mathrm{mg} / \mathrm{kg}]}\end{array}$ & $\begin{array}{c}\mathrm{Ca} \\
{[\mathrm{mg} / \mathrm{kg}]}\end{array}$ & $\begin{array}{c}\mathrm{Mg} \\
{[\mathrm{mg} / \mathrm{kg}]}\end{array}$ & $\begin{array}{c}\mathrm{P} \\
{[\mathrm{mg} / \mathrm{kg}]}\end{array}$ \\
\hline Fungal chitosan & $1.93 \pm 0.02$ & $0.53 \pm 0.06$ & $2.89 \pm 0.17$ & $0.41 \pm 0.0033$ & $0.08 \pm 0.005$ \\
\hline $\begin{array}{l}\text { Crustaceous chitosan } \\
\text { of low molecular weight }\end{array}$ & $2.73 \pm 0.10$ & $0.47 \pm 0.07$ & $2.10 \pm 0.002$ & $0.26 \pm 0.002$ & $0.033 \pm 0.0033$ \\
\hline $\begin{array}{l}\text { Crustaceous chitosan } \\
\text { of average molecular } \\
\text { weight }\end{array}$ & $8.60 \pm 0.43$ & $0.15 \pm 0.06$ & $6.82 \pm 1.49$ & $0.28 \pm 0.02$ & $0.11 \pm 0.0033$ \\
\hline $\begin{array}{l}\text { Crustaceous chitosan } \\
\text { of high molecular } \\
\text { weight }\end{array}$ & $3.50 \pm 0.07$ & $0.13 \pm 0.03$ & $0.91 \pm 0.28$ & $1.94 \pm 0.04$ & $0.01 \pm 0.0003$ \\
\hline Fungal chitin & $19.93 \pm 0.14$ & $11.65 \pm 0.005$ & $310.87 \pm 2.59$ & $31.50 \pm 0.37$ & $1.74 \pm 0.0088$ \\
\hline
\end{tabular}

\pm standard deviation

Values in column with different letter are significantly different at $p \leq 0.05$

Fungal chitosan was characterized by the highest amount of potassium $-0.53 \mathrm{mg} / \mathrm{kg}$, while chitosan of high molecular weight obtained from crustaceous shells contained four times less potassium $-0.13 \mathrm{mg} / \mathrm{kg}$. In crustaceous chitosans of low and average molecular weight the content of potassium ranged from $0.15 \mathrm{mg} / \mathrm{kg}$ to $0.47 \mathrm{mg} / \mathrm{kg}$.

Calcium content in fungal chitosan was three times higher $(2.90 \mathrm{mg} / \mathrm{kg})$ than in crustaceous chitosan of high molecular weight $(0.91 \mathrm{mg} / \mathrm{kg})$.

Fungal chitosan contained lower level of magnesium $(0.40 \mathrm{mg} / \mathrm{kg})$ than crustaceous chitosan of high molecular weight $(1.94 \mathrm{mg} / \mathrm{kg})$. Chitosans obtained from crustaceans of low and average molecular weight were characterized by lower content of magnesium $(0.26 \mathrm{mg} / \mathrm{kg}, 0.28 \mathrm{mg} / \mathrm{kg}$ respectively).

Fungal chitosan contain more phosphorus $(0.08 \mathrm{mg} /$ $\mathrm{kg}$ ) than chitosan obtained from crustaceous shells of high molecular weight $(0.01 \mathrm{mg} / \mathrm{kg})$.

Levels of selected minerals were also investigated in fungal chitin. In this substance, the highest levels of all mentioned elements were observed. High values of individual mineral components in fungal chitin are considered to be evidence for key-role of deacetylation process.

Carbon, nitrogen and hydrogen contents, as well as the N/C ratio, significantly increased in custaceous chitosan as a result of $N$-deacetylation process. The highest level of carbon was noted in fungal chitosan $-40.86 \%$, whereas in crustaceous chitosan this level was $40.58 \%$. Both fungal and crustaceous chitosans contained similar values of hydrogen and ranged from 6.95 to $6.96 \%$. In crustaceous chitosan, lower amounts of nitrogen were observed (7.19\%), compared to fungal chitosan (7.56\%). The highest value of $\mathrm{N} / \mathrm{C}$ ratio was noted in fungal chitosan $(0.18 \%)$, whereas in fungal chitin this ratio was the lowest $-0.87 \%$. This result may indicate that the process of $\mathrm{N}$-deacetylation has resulted in increase of mineral elements content.

The basic descriptive viscosity characteristics of $1 \%$ solution of crustaceous and fungal chitosans is presented in Table 4. Viscosity of fungal chitosan was almost five times lower $(58.0 \mathrm{cP})$ than that of crustaceous chitosan $(262.1 \mathrm{cP})$. Analysis of variance confirmed statistical sig-

TABLE 3. Percentages of the three elements $\mathrm{C}, \mathrm{H}, \mathrm{N}$ and N/C ratio, determined with the Perkin Elmer 2400 analyser

\begin{tabular}{|c|c|c|c|c|}
\hline Sample & $\% \mathrm{C}$ & $\% \mathrm{H}$ & $\% \mathbf{N}$ & $\mathrm{N} / \mathrm{C}$ \\
\hline \multirow[t]{3}{*}{ Fungal chitosan } & 40.85 & 6.98 & 7.58 & 0.16 \\
\hline & $40.86 \pm 0.01$ & $6.95 \pm 0.02$ & $7.56 \pm 0.02$ & \\
\hline & 40.88 & 6.93 & 7.55 & \\
\hline \multirow[t]{3}{*}{ Crustaceous chitosan of high molecular weight } & 40.57 & 6.96 & 7.18 & 0.18 \\
\hline & $40.58 \pm 0.02$ & $6.96 \pm 0.01$ & $7.19 \pm 0.02$ & \\
\hline & 40.60 & 6.97 & 7.21 & \\
\hline \multirow[t]{3}{*}{ Fungal chitin } & 38.11 & 6.12 & 3.31 & 0.09 \\
\hline & $38.16 \pm 0.01$ & $6.16 \pm 0.01$ & $3.32 \pm 0.02$ & \\
\hline & 38.22 & 6.21 & 3.33 & \\
\hline
\end{tabular}


TABLE 4. Basic descriptive characteristics of the measurement of chitosan coefficient of viscosity

\begin{tabular}{|l|c|c|c|c|}
\hline Sample & Mean [CP] & Standard deviation & Variance & Standard error \\
\hline $\begin{array}{l}\text { Crustaceous chitosan of high } \\
\text { molecular weight }\end{array}$ & 262.10 & 1.57 & 2.46 & 0.70 \\
\hline Fungal chitosan & 58.00 & 0.65 & 0.43 & 0.29 \\
\hline
\end{tabular}

nificance of differences between viscosity of analyzed chitosans (at $\alpha=0.05$ ). The viscosity of molecular weight was calculated according to the method presented above.

The viscosity molecular weight of crustaceous chitosan was almost six times higher, compared to fungal chitosan (Fig. 3). The mean viscosity of fungal chitosan molecular weight was $69.9 \mathrm{kDa}$, while for crustaceous chitosan $354.2 \mathrm{kDa}$.

The results of $\mathrm{CHN}$ analysis were used for calculations. Fungal chitosan had higher deacetylation degree (DD), compared to crustaceous chitosan. The deacetylation degree is a parameter which may be regulated based on duration of the deacetylation process. The longer time of $\mathrm{N}$-deacetylation, the higher degree of deacetylation. Similar conclusions have been presented by Yen and Mau [27].

The results of deacetylation degree of fungal and crustaceous chitosans are shown in Table 5. Fungal chitosan possessed a higher deacetylation degree (84.61\%) than crustaceous chitosan $(70.76 \%)$. The process of $\mathrm{N}$-deacetylation is important factor influencing solubility of chitosan. The more deacetylized chitosan, the better it is dissolved, therefore its application is easier. The deacetylation degree of crustaceous chitosan evidenc-

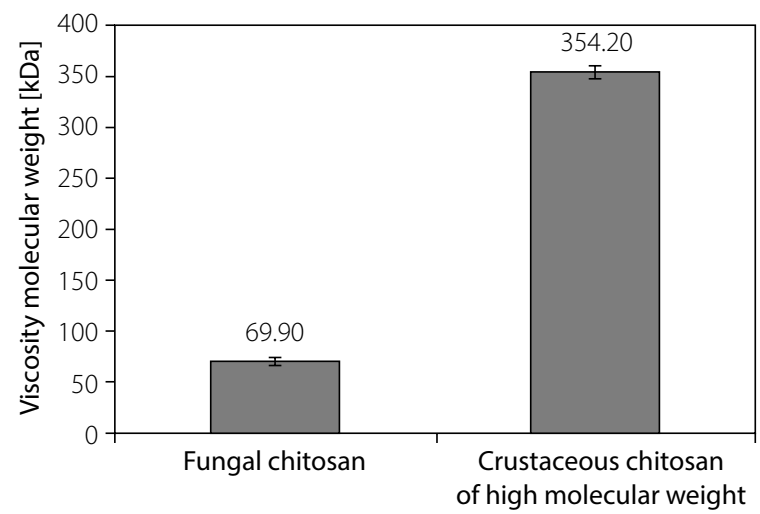

FIGURE 3. Differences in viscosity molecular weight between crustaceous and fungal chitosans es too short reaction time. The results of a number of studies, including DD analysis confirm, that crustaceous chitosan is characterized by higher deacetylation degree than fungal one $[25,28]$.

Dry mass in the chitosans in the study ranged from 86.77 d.m. in crustaceous chitosan of high molecular mass to $91.79 \mathrm{~d} . \mathrm{m}$. in chitosan of mediocre molecular mass, whereas fungal chitosan contained $89.42 \%$ of dry mass. The contents of ash was from $0.20-0.50 \%$ in crustaceous chitosan to $0.3 \%$ in fungal chitosan. Similar results were obtained by Shepherd et al., where the contents of ash ranged from $0.17 \%$ to $0.58 \%$ [15]. Humidity in fungal chitosan was $10.60 \%$, while in crustaceous chitosan ranged from $8.20 \%$ to $13.23 \%$.

Similar results were presented by Shepherd et al. [15]. Results of humidity in fungal and crustaceous chitosans ranged from 2.10 to $12.90 \%$.

Fungi, to synthetize nitrogen in their walls, require an organic or inorganic source of this element in their nutrition. Ammonium ion may be the direct source of nitrogen in fungi nutrition, because an inorganic form of nitrogen is reduced during the redox reaction to ammonium. The source of nitrogen is one of the most important factors in the production of chitosan by fungi [29]. Based on results presented in Table 1, it may be presumed that fungal chitosan has higher contents of fat $(0.38 \%)$ and fiber $(4.60 \%)$, than crustaceous chitosans (0.10-0.29\% fat; $1.40-3.90 \%$ fiber), whereas fungal chitin was characterized by a higher content of fat (1.04\%) and fiber (77.91\%), compared to chitosans. Based on these results, degradation of chitosan chemical composition in $\mathrm{N}$-deacetylation process can be assessed. Similar observations were made by Yen et al. [27].

Following $\mathrm{N}$-deacetylation process a product containing more than $7.00 \%$ of nitrogen is classified as chitosan [11]. Fungal chitosan contained $7.56 \%$ of nitrogen, whereas crustaceous chitosan $7.18 \%$. Similar effect was observed by Yen, Yang, Mau, 2009 [30].

The analysis of selected minerals had shown (Table 2) that fungal chitosan was characterized by the highest

TABLE 5. Basic values in calculating DD - deacetylation degree

\begin{tabular}{|l|c|c|c|c|}
\hline Sample & $\begin{array}{c}\text { Carbon content } \\
{[\%]}\end{array}$ & $\begin{array}{c}\text { Nitrogen content } \\
{[\%]}\end{array}$ & $\begin{array}{c}\text { Ratio C/N } \\
{[\%]}\end{array}$ & $\begin{array}{c}\text { Deacetylation } \\
\text { degree [\%] }\end{array}$ \\
\hline $\begin{array}{l}\text { Crustaceous chitosan of high } \\
\text { molecular weight }\end{array}$ & 40.58 & 7.19 & 5.643 & 70.76 \\
\hline Fungal chitosan & 40.86 & 7.56 & 5.404 & 84.61 \\
\hline
\end{tabular}


amount of potassium $0.53 \mathrm{mg} / \mathrm{kg}$, while crustaceous chitosan of high molecular mass contained four-times less potassium $(0.12 \mathrm{mg} / \mathrm{kg})$. Crustaceous chitosan of mediocre molecular mass was characterized by the highest content of sodium $(8.60 \mathrm{mg} / \mathrm{kg})$, while in fungal chitosan merely $1.93 \mathrm{mg}$ of sodium per kilogram, and in crustaceous chitosan of high molecular mass twice as much $(3.50 \mathrm{mg} / \mathrm{kg}$ ) were found. Fungal chitosan was characterized by 3 -fold higher contents of calcium $(2.90 \mathrm{mg} /$ $\mathrm{kg}$ ), compared to crustaceous chitosan of high molecular mass $(0.91 \mathrm{mg} / \mathrm{kg})$.

It was noted that fungal chitosan had lower content of magnesium $(0.41 \mathrm{mg} / \mathrm{kg})$, than crustaceous chitosan of high molecular mass $(1.94 \mathrm{mg} / \mathrm{kg})$.

Fungal chitosan was characterized by a higher contents of phosphorus $(0.08 \mathrm{mg} / \mathrm{kg})$, compared to crustaceous chitosan of high molecular mass $(0.01 \mathrm{mg} / \mathrm{kg})$.

In fungal chitin, the highest contents of all the investigated elements were observed $(\mathrm{Na}-19.93 \mathrm{mg} / \mathrm{kg}, \mathrm{K}$ - $11.65 \mathrm{mg} / \mathrm{kg}, \mathrm{Ca}-310.88 \mathrm{mg} / \mathrm{kg}, \mathrm{Mg}-31.50 \mathrm{mg} / \mathrm{kg}$, and $\mathrm{P}-1.74 \mathrm{mg} / \mathrm{kg}$ ). It may be concluded that $N$-deacetylation process has an enormous effect on the contents of mineral elements. Similar results were obtained by Tolaimate et al. [31].

The results presented in Table 3 had confirmed that $\mathrm{N}$-deacetylation process exerted a significant effect on the contents of carbon and hydrogen, as well as on the N/C ratio, that considerably increased with respect to fungal chitin. The highest content of carbon was found in fungal chitosan (40.86\%). Fungal and crustaceous chitosans had similar hydrogen contents ranged from $6.93 \%$ to $6.98 \%$. In crustaceous chitosan nitrogen content was lower (7.19\%), compared to fungal chitosan (7.56\%). The N/C ratio was the highest in fungal chitosan $(0.18 \%)$, whereas in fungal chitin this ratio was the lowest $(0.08 \%)$. These results may indicate that $N$-deacetylation process leads to increase of selected mineral elements. Similar results were obtained by Yen et al. [27] and by Guo et al. [32].

Our studies had shown (Table 4), that fungal chitosan was characterized by viscosity of the value of $58.0 \mathrm{cP}$ (centipoises), whereas crustaceous chitosan - $262.1 \mathrm{cP}$. The viscosity of fungal chitosan was nearly five times lower than that of crustaceous chitosan. Low viscosity of fungal chitosan may be associated with its high deacetylation degree. Other authors also conluded that the higher deacetylation level, the lower viscosity. Therefore, it may be concluded that the duration of deacetylation process affects also viscosity. Similar results were obtained by Chen et al. [25], Chang et al. [28], and Rogovina et al. [33]. Significant differences were also observed in the results of chitosan viscosity (Table 4).

Based on the empirical calculations of the viscosity of molecular mass (Fig. 3) it was found that crustaceous chitosan had a higher value than fungal one. The viscosity of molecular mass of fungal chitosan was $69.9 \mathrm{kDa}$ and was almost seven times lower than the viscosity of the molecular mass of crustaceous chitosan $-354.2 \mathrm{kDa}$. The viscosity of chitosan molecular mass depends on deacetylation degree of this polymer. It should be adopted that the longer deacetylation time, the lower $\mathrm{Mv}$, and higher deacetylation degree when one is considering this rule. Fungal chitosan was characterized by a high degree of deacetylation, which confirmed the calculations of the viscosity of molecular mass. Similar results were obtained by Chen et al. [25], Chang et al. [28], Rogovina et al. [33].

\section{CONCLUSIONS}

1. Fungal chitosan was characterized by a higher contents of nitrogen, fiber and fat, compared to crustaceous chitosan.

2. Fungal chitosan had lower viscosity and molecular mass viscosity than crustaceous chitosan.

3. Fungal chitosan had higher deacetylation degree than crustaceous chitosan.

4. The process of $\mathrm{N}$-deacetylation exerted significant effect on the structure and properties of fungal chitosan. The longer duration of deacetylation process, the higher the deacetylation degree, and the lower chitosan viscosity.

\section{DISCLOSURE}

Authors report no conflict of interest.

\section{References}

1. Da Silva LCA, Honorato TL, Franco TT, et al. Optimization of chitosanase production by Trichoderma koningii sp. under solid-state fermentation. Food Bioprocess Technol 2010; DOI 10.1007/s11947-010-0479-1.

2. Shahidi F, Arachchi JKV, Jeon YJ. Food applications chitin and chitosans. Trends Food Sci Technol 1999; 10: 37-51.

3. Knorr D. Recovery and utilization of chitin and chitosan in food processing waste management. Food Technol 1991; 45: 114-122.

4. Allan CP, Hadwiger LA. The fungicidal effect of chitosan on fungi of varying cell wall composition. Exp Mycol 1979; 3: 285-287.

5. Kumar MNVR. A reviev of chitin and chitosan aplications. Reactive \& Functional Polymers 2000; 46: 1-27.

6. Cabib E. Chitin: structure, metabolism and regulation of biosynthesis. Encyclopedia of Plant Physiology 1981; 13: 395-415.

7. Han LK, Kiura Y, Okuda H. Reduction in fat storage during chitin-chitosan treatment in a mice fed high-fat diet. International Journal of Obesity 1996; 23: 174-179.

8. Jang MK, Kong B-G, Jeong Y-I, Lee CH, Nah J-W. Physicochemical characterization of $\alpha$-chitin, $\beta$-chitin and $\gamma$-chitin separated from natural resources. Journal of Polymer Science, Part A: Polymer Chemistry. 2004; 42: 3423-3432.

9. Jaworska MM. Chitosan from mucorales, Chitin and chitosan. Polish-Russian Monograph, Polish Chitin Society, Łódz, 1999: 23-32 (in Polish).

10. White SA, Farina PF, Fulton I. Production and isolation of chitozan from Mucor rouxii. Applied and Environmental Microbiology 1979; 38: 323-328. 
11. Muzzarelli RAA, Rocchetti R. Determination of the degree of acetylation of chitosans by first derivative Ultraviolet spectrophotometry. Carbohydrate Polymers 1985; 5: 461-472.

12. Yen MT, Mau JL. Preparation of fungal chitin and chitosan from shiitake stipes. Fungal Science 2006; 21: 1-11.

13. Draczynski Z. Honeybee corpses as an available source of chitin. Journal of Applied Polymer Science 2008; 109: 1974-1981.

14. Pochanavanich P, Suntornsuk W. Fungal chitosan production and its characterization. Letters in Applied Microbiology 2002; 35: $17-21$.

15. Shepherd R, Readre S, Falshaw A. Chitosan functional properties. Glycoconjugate Journal 1997; 14: 535-542.

16. Kalbarczyk J, Żukiewicz-Sobczak W. Production of fungi chitosan 2008; Patent P-384836 (in Polish).

17. AACC (1990). Approved Methods.

18. AOAC - Association of Official Analytical Chemists. Official methods of analysis. Association of Analytical Chemists International, Washington 1995.

19. AOAC - Association of Official Analytical Chemists. Official methods of analysis. Association of Official Analytical Chemists, Washington, 2002.

20. AOAC - Association of Official Analytical Chemists. Official methods of analysis. Association of Official Analytical Chemists. Washington, 2006.

21. Fiske $\mathrm{CH}$, Subbarow Y. The colourimetric determination of phosphorus. J Biol Chem 1925; 66: 375-400.

22. Brunauer S, Emmett PH, Teller E. Adsorption of gases in multimolecular layers. J Am Chem Soc 1938; 60: 309-319.

23. Gregg SJ, Sing KSW. Adsorption, surface area and porosity. Academic Press, London 1967.
24. Barrett EP, Joyner LG, Halenda PH. The determination of pore volume and area distributions in porous substances-I. Computations from nitrogen isotherms. J Am Chem Soc 1951; 73: 373-380.

25. Chen CH, Wang FY, Ou ZP. Deacetylation of $\beta$-chitin. I. Influence of the deacetylation conditions. J Appl Polymer Sci 2004; 93: 2416-2422.

26. Xu J, McCarthy SP, Gross RA. Chitosan film acylation and effects on biodegradability. Macromolecules 1996; 29: 3436-3440.

27. Yen MT, Mau JL. Physico-chemical characterization of fungal chitosan from shiitake stipes. LWT - Food Science and Technology 2007; 40: 472-479.

28. Chang MC, Ko CC, Douglas WH. Preparation of hydroxyapatite-gelatin nanocomposite. Biomaterials 2003; 24: 2853-2862.

29. Moore-Landecker E. Fundamentals of the fungi. Prentice-Hall, Englewood Cliffs 1996; 251-278.

30. Yen MT, Yang JH, Mau JL. Physicochemical characterization of chitin and chitosan from crab shells. Carbohydrate Polymers 2009; 75: 15-21.

31. Tolaimate A, Desbrieres J, Rhazi M, Alagui A. Contribution to the preparation of chitins and chitosans with controlled physico-chemical properties. Polymer 2003; 44: 7939-7952.

32. Guo Z, Liu H, Chen X, Ji X, Li P. Hydrocsyl radicals scavening activity of $\mathrm{N}$-substituted chitozan and quaternized chitosan. Bioorganic \& Medicinal Chemistry Letters 2006; 16: 6348-6350.

33. Rogovina SZ, Akopova TA, Vikhoreva GA. Investigation of properties of chitosan obtained by solid-phase and suspension methods. Journal of Applied Polymer Science 1998; 70: 927-933. 